\title{
Environmental impact assessment of the surrounding areas of urban forests
}

\author{
R. M. Longo ${ }^{1}$, A. L. Mulato ${ }^{1}$, T. A. M. Misono ${ }^{1}$, M. F. Silva ${ }^{1}$, \\ A. C. Demamboro ${ }^{1}$, S. C. Betine ${ }^{1} \&$ A. I. Ribeiro ${ }^{2}$ \\ ${ }^{1}$ Ceatec-Center for Science, Technology and Environmental, \\ Pontifical Catholic University of Campinas - SP, Brazil \\ ${ }^{2}$ University of the State of São Paulo, UNESP, Brazil
}

\begin{abstract}
This study aimed to investigate some of the characteristics of the soil in areas edging forests located in an urban area in Campinas/SP, Brazil, in order to check whether or not there was any negative interference arising from the use and occupation of soil in its vicinity, called 'edge effects'. For both samples of soil in the field, laboratorial analysis was performed. By studying all the factors, it was observed that the soil in all the remaining edges was found to be physically unstructured. Statistical analysis showed that it is not possible to indicate which use or occupation is presented as more degrading, since the analyzed data had high coefficients of variation around its perimeter. However, from the literature review relating to the results, it can be seen that the loss of soil structure is an indicator of degradation as well as high levels of low density and compaction in seeds found. With regard to the compaction of the soil, it was found that this parameter can be used as an indicator of the quality of the soil, whereas, to this end, the local peculiarities were always observed, while performing an analysis in the most comprehensive and complete way as possible.
\end{abstract}

Keywords: remaining urban forest, soil degradation, environmental impact.

\section{Introduction}

Knowledge of remnant native vegetation of a region and its relationship with the soil that supports it can assist in the maintenance and use of the biodiversity of these ecosystems. A great challenge for science today is the preservation of natural environments, which are under pressure anthropogenically, resulting in fragmentation and modification [1]. 
The most common reasons for why deforestation takes place are in order to use timber and to make way for the development of agricultural activities that permit the production of food to support a growing human population [2]. The fragmentation of vegetation exists simply because this is necessary for the survival of man himself, and degrading the forest to expand for production leads to soil depletion. Brazil shows a wide variety of terrestrial biomes, each with unique characteristics, and many of the populations and their attributes are also, correspondingly, limited according to each macro-region. Furthermore, within the biomes, there is a variety of ecoregions, many of which have very specific ecological processes [1].

The Brazilian continental biomes are: Amazon, Cerrado, Atlantic Forest, Caatinga, Pantanal and Pampas. Among these, the most important are the Amazon, Cerrado and Atlantic Forest, due to the amount of land mass they occupy and their biological diversity. Limited knowledge about the diversity of these biomes, together with the movements of degradation imposes the need for an investigation into the main species residing in either natural conditions or in degraded areas, with an analysis of the consequences of degradation, or even of different tillage systems used in these areas [3]. The analysis of biological diversity in degraded areas also becomes important. Therefore, in order to understand and estimate the recovery of the same, there must be an adequate understanding of the environmental conditions present before, during and after a certain impact [3].

Besides its intrinsic value as a member of biological diversity, soil fauna enables the observation of each individual without the need for special support resources. Another favorable condition is that the collection methods employed in the field are relatively simple, although some restrictions or limitations may be introduced [3].

Despite the existence of sustainable forestry and agricultural techniques, capable of increasing the productivity of land without the incorporation of new areas, the agricultural frontier continues to advance, contributing to a loss of biodiversity, fertility, organic matter and soil microorganisms, and compacting [2]. In some areas of degradation, soil itself is no longer present, just a little mineral and organic material and very small amounts of plant nutrients reside, which can be reinstated to form vegetation cover, to start again the process of soil formation through chemical changes along with the physical and biological properties.

The goal of this work is to perform an analysis of macronutrients and soil macrofauna in the forest, pasture and sugar cane and to draw conclusions about the impacts of cattle farming and urban expansion on a forest in terms of the chemical aspects of soil.

\section{Methodology}

The forest of Quilombo, characterized by the "cerrado" vegetation found, is located in the Village of Florida north of Barão Geraldo, in the northwestern portion of the city of Campinas/SP, Brazil. 
A preliminary characterization of the study area was carried out through working directly in the field, where key areas of native forest areas with spontaneous vegetation were identified, along with areas of pasture and sugar cane. Hence, we opted for the assessment of the interference of pasture and sugar cane in remnant forests, using the analysis of soil fertility and soil macrofauna as our main parameter. In all areas of identifying the analyzed parameters, these can serve as indicators of biological and chemical degradation in urban forest remnants. The local soil is classified as Oxisols purple [4].

28 soil samples were collected in the border areas of remaining forest. Initial steps involved the cleaning of the collection site, removing the surface vegetation, roots and other debris, and then we began the process of collecting samples with the aid of a spade to a depth of $0.20 \mathrm{~m}$. The samples were collected in triplicate, stored in a plastic bag, and then sealed and identified by a label that specified the allocated number for the point of collection. Figure 1 shows the sampling points, arranged numerically.

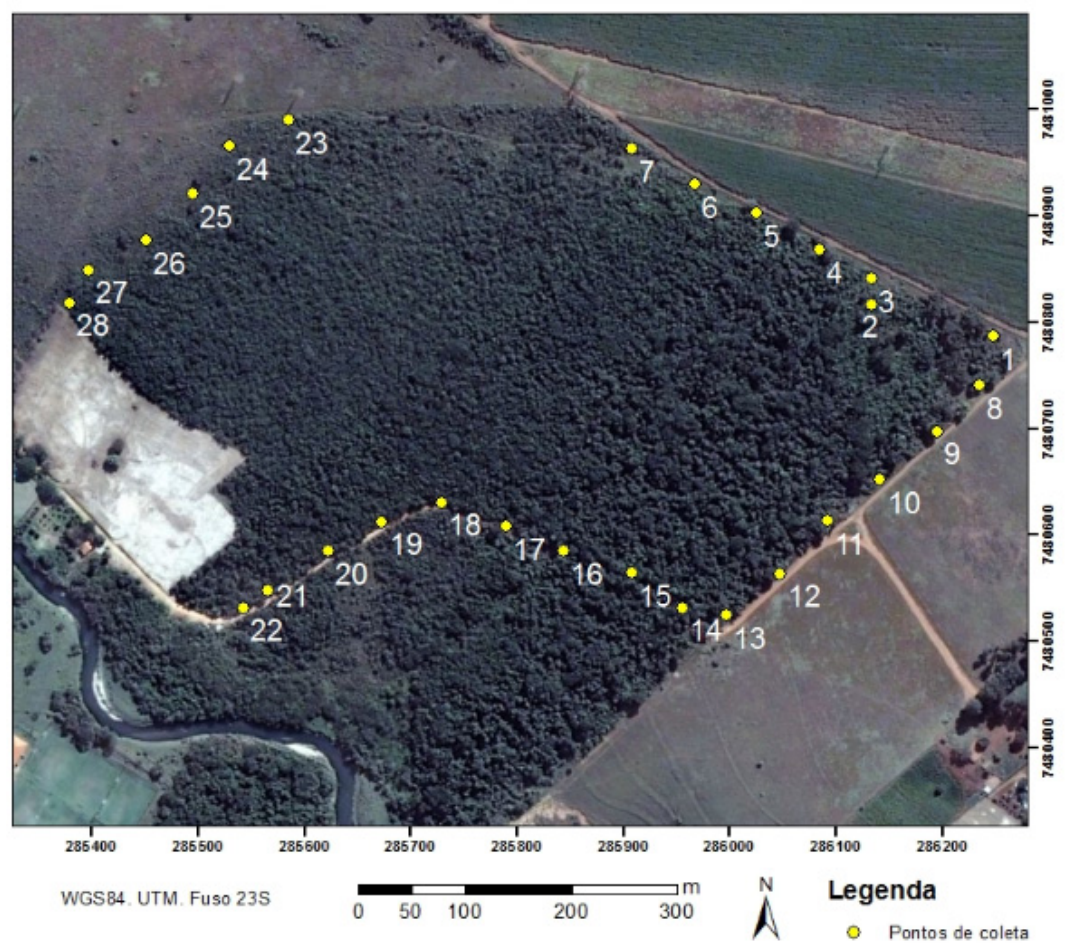

Figure 1: Soil collection points. (Source: Bing Maps Aerial 2010, without real value mapping. Edited by: REIS, M.S.)

At each sampling point, four composite samples were collected at a depth of $0-20 \mathrm{~cm}$. The prepared samples were analyzed for: soil density phosphorus $(\mathrm{P})$, humidity, organic matter $(\mathrm{OM})$ and seeds. For the characterization of the seed bank 
a soil sample in the center of each sub-plot $\left(1 \mathrm{~m}^{2}\right)$ was collected, totaling to 28 samples, with a metallic ring hollow $11.5 \mathrm{~cm}$ high and $11.1 \mathrm{~cm}$ in diameter with an area of approximately $0.0967 \mathrm{~m}^{2}$.

\section{Results and discussion}

In general, it can be noted that areas of planted sugar cane and pasture mainly surround the forest fragment. The Wastewater Treatment Station, Barão Geraldo, is located in one of the sampled sections from the forest edge, which was partly responsible for the deforestation of the area and the constant odor and noise that scared some species of wildlife. It was also observed that the forest is in a state of degradation, containing areas of landfill along with several other sites that were found burned. Thus, the area is suffering from a very sharp anthropogenic pressure in its border areas, which has direct impacts on the soil, vegetation and fauna. Thus, for the degradation to be stopped then it must be immediately isolated and the remaining areas that allow open access to the population and vandals must be impounded.

An urban forest fragment can be considered as a fragile ecosystem simply by being isolated and exposed to external actions, such as the edge effect and human exploits. Thus, the forest of Quilombo is no exception to this rule. Even though they are aggravating, it should be noted that forests that are not yet consolidated, i.e. those who have not yet reached their climax, are more vulnerable to adverse conditions.

It should be noted that soil degradation occurs when the negative aspects caused by the use and occupation of land outweigh the positives generated by these uses. Human action in central areas has proven very invasive, proving to be very intense and carried out in short time interventions. Thus, the resilience of the soil is much lower than what would be needed to reverse the situation, and it is unable to regenerate or support such interventions without passing through profound changes detrimental to the ecosystem.

In Table 1 and Figure 2 it is observed that the variation of the parameters analyzed in this study are presented heterogeneously throughout the forest edge in order for it to be evident that the use and occupation of land around these areas is interfering with the soil quality in the forest. Hence, we observe high values of soil density in some areas and decreasing levels of organic matter in others. The other indexes showed large variations, indicating a loss of soil physical structure. However, when analyzing only the organic matter, it is observed that areas next to the cultivation of sugar cane (points 1-8) have the highest value. This area probably receives a management that facilitates the development of plants, soil improvement and fertilizer when needed. The adjacent road causes the land to be extremely exposed to adverse conditions such as tank construction, lightweight and heavy traffic and animal material, without receiving any care or management. 
Table 1: $\quad$ Parameters of soil in areas of edges in urban forests.

\begin{tabular}{|c|c|c|c|c|c|c|}
\hline Points & $\begin{array}{l}\text { Soil } \\
\text { density }\end{array}$ & $\begin{array}{l}\text { Organic } \\
\text { matter } \\
(\mathrm{OM})\end{array}$ & Humidity & $\begin{array}{l}\text { Phosphorous } \\
\text { (P) }\end{array}$ & Seeds & \\
\hline & $\mathrm{gf} / \mathrm{cm}^{3}$ & $\mathrm{~g} / \mathrm{dm}^{2}$ & $\%$ & $\mathrm{mg} / \mathrm{dm}^{2}$ & seeds $/ \mathrm{m}^{2}$ & Species \\
\hline 1 & 1.118 & 47 & 22.293 & 2 & 0 & 0 \\
\hline 2 & 1.464 & 48 & 22.323 & 2 & 0 & 0 \\
\hline 3 & 0.908 & 47 & 22.79 & 5 & 0 & 0 \\
\hline 4 & 1.484 & 46 & 21.396 & 4 & 104.2 & 3 \\
\hline 5 & 1.331 & 90 & 21.118 & 19 & 20.8 & 1 \\
\hline 6 & 1.484 & 80 & 20.453 & 6 & 41.7 & 1 \\
\hline 7 & 1.25 & 55 & 17.391 & 5 & 0 & 0 \\
\hline 8 & 1.316 & 63 & 17.457 & 5 & 62.5 & 2 \\
\hline 9 & 1.533 & 56 & 17.384 & 31 & 104.2 & 1 \\
\hline 10 & 1.538 & 42 & 18.885 & 5 & 20.8 & 1 \\
\hline 11 & 1.325 & 63 & 18.503 & 4 & 0 & 0 \\
\hline 12 & 1.181 & 49 & 18.82 & 4 & 0 & 0 \\
\hline 13 & 1.377 & 70 & 32.496 & 5 & 0 & 0 \\
\hline 14 & 1.117 & 62 & 30.526 & 6 & 0 & 0 \\
\hline 15 & 1.104 & 59 & 30.984 & 6 & 0 & 0 \\
\hline 16 & 0.989 & 67 & 27.848 & 12 & 0 & 0 \\
\hline 17 & 1.112 & 42 & 27.048 & 5 & 0 & 0 \\
\hline 18 & 1.469 & 46 & 27.107 & 6 & 0 & 0 \\
\hline 19 & 1.762 & 44 & 16.853 & 5 & 0 & 0 \\
\hline 20 & 1.684 & 32 & 17.894 & 3 & 0 & 0 \\
\hline 21 & 1.553 & 25 & 17.319 & 2 & 0 & 0 \\
\hline 22 & 1.4 & 55 & 21.531 & 12 & 0 & 0 \\
\hline 23 & 1.379 & 40 & 21.271 & 5 & 31.2 & 1 \\
\hline 24 & 1.332 & 35 & 21.367 & 3 & 0 & 0 \\
\hline 25 & 1.257 & 41 & 24.281 & 4 & 52.1 & 1 \\
\hline 26 & 1.329 & 49 & 23.189 & 1 & 0 & 0 \\
\hline 27 & 1.413 & 36 & 23.16 & 1 & 114.6 & 3 \\
\hline 28 & 1.607 & 47 & 19.173 & 2 & 41.7 & 1 \\
\hline
\end{tabular}

The recovery of soil structure becomes more difficult and time-consuming the more deteriorated the analyzed area. A degraded soil also influences the species that inhabit it. Some changes may result in the loss of biodiversity, because species may be lost in that environment or migrate to more open areas with suitable conditions for survival, as it can be seen from the data obtained from the analysis of the seed bank and the number of species (Figure 2). The term seed bank is used to designate the reservation of viable seeds in the soil [5]. For [6], this corresponds to the notion that reservation seeds do not germinate, but are able to replenish adult plants, which by chance, were suppressed in some way by the environment. 
506 Sustainable Development and Planning VII

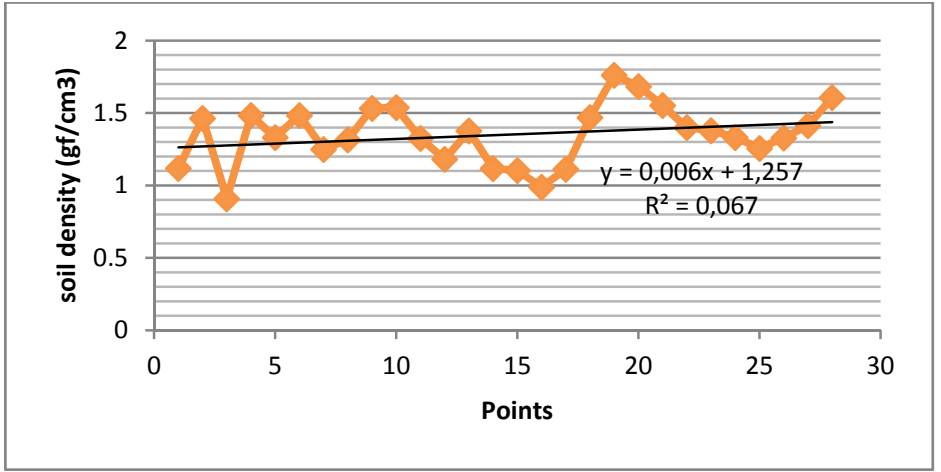

(a)

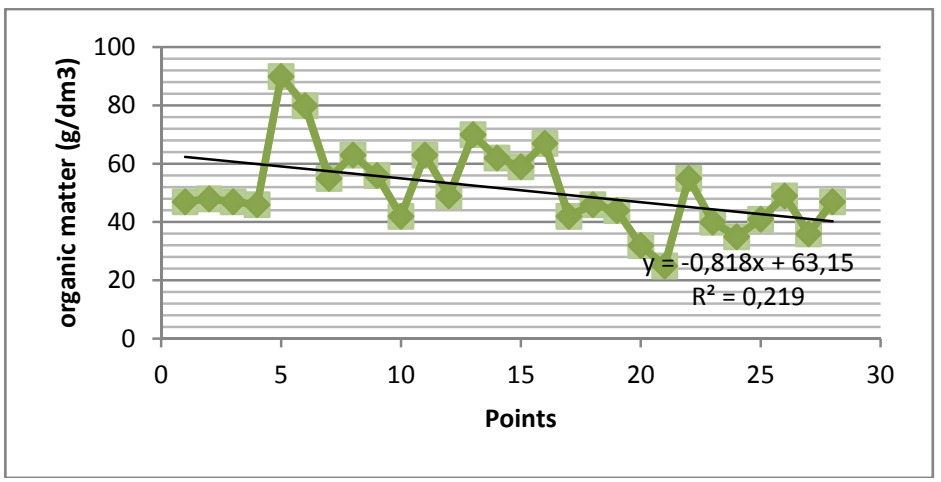

(b)

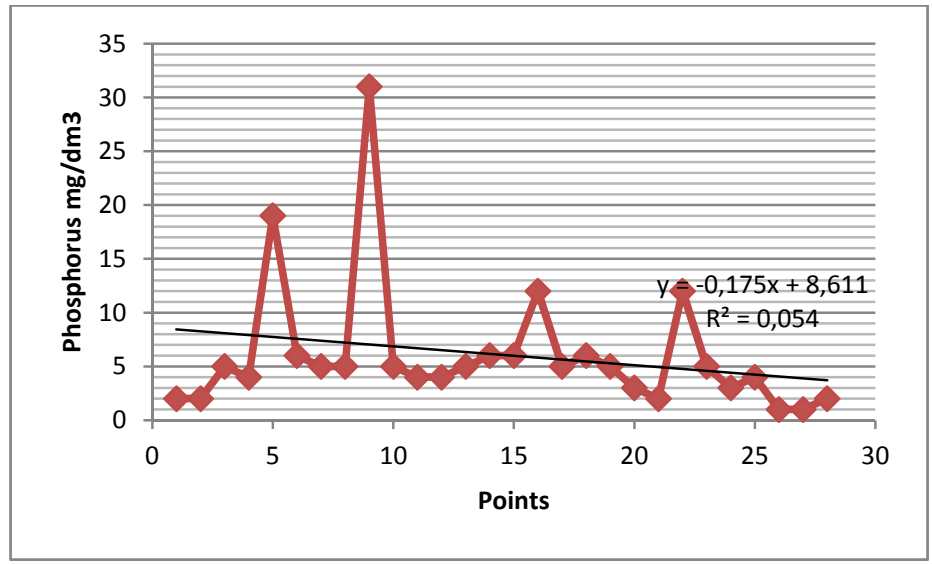

(c)

Figure 2: Evolution of parameters of soil in areas of edges in urban forests. 


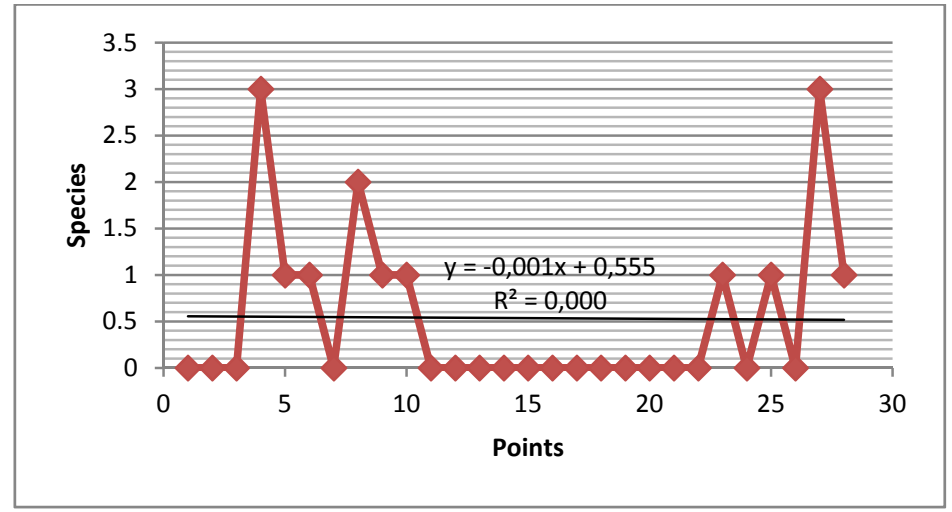

(d)

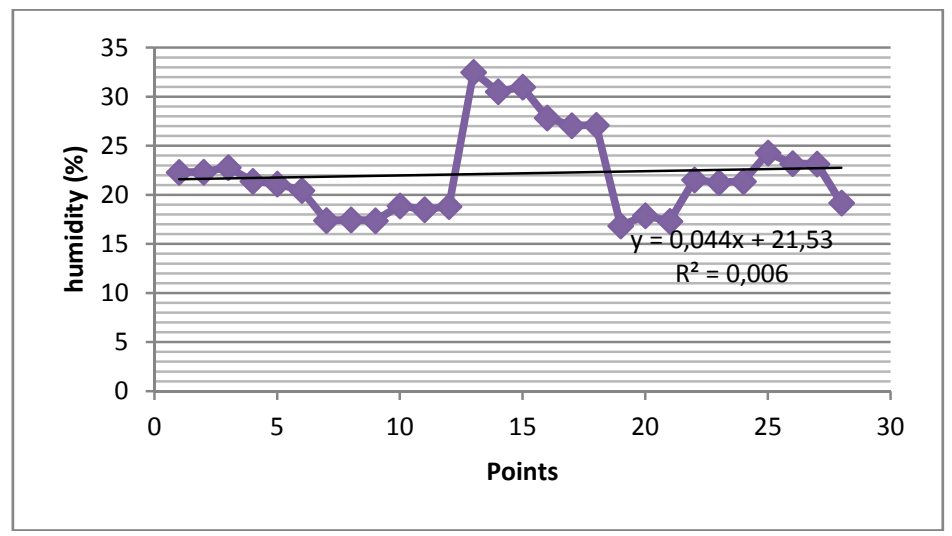

(e)

Figure 2: Continued.

In this context, it is of the utmost importance to efficiently recover a degraded soil quickly due to the importance of forest dynamics and ecosystem survival. At this point we observe the importance for the existence of efficient public policies in order to sustain and finance projects aimed at preserving green areas and other protected areas.

\section{Conclusion}

Analyzing all the factors in an integrated way, we can conclude that soil quality is central to the existence of the ecosystem and also decisively influences the potentials for land use and their levels of productivity. 


\section{Acknowledgements}

The Pontifical Catholic University of Campinas (PUC-Campinas), and the Foundation for Supporting Research in the state of São Paulo (FAPESP).

\section{References}

[1] Borges, L. F. R. et al. Inventário de fragmentos florestais nativos e propostas para seu manejo e o da paisagem. 2004. 18f. Universidade Federal de Lavras, Lavras, 2004.

[2] Martins, I.C.M., et al. Caracterização ambiental de fragmentos florestais naturais - "ipucas" - no Município de Lagoa da Confusão, Tocantins. In: Anais X Simpósio Brasileiro De Sensoriamento Remoto, 21-26 abril 2001, INPE, p. 1657-1664. Foz do Iguaçu, 2001.

[3] Santin, D.A. A vegetação remanescente do município de Campinas (SP): mapeamento, caracterização fisionômica e florística, visando a conservação. 1999. 70f. Tese de doutorado em Ciências Biológicas. Universidade Estadual de Campinas, Campinas, 1999.

[4] Plano Local de Gestão Urbana de Barão Geraldo. Prefeitura Municipal de Campinas. Secretaria de Planejamento e Meio Ambiente, 1996.

[5] Baker, H.G. Some aspects of the natural history of seed banks. In: Leck, M.A.; Parker, V.T.; Simpson, R.L. (Ed) Ecology of soil seed banks. London: Academic Press, p. 5-19, 1989.

[6] Roberts, H.A. Seed banks in the soil. Advances in Applied Biology, Cambridge, Academic Press, 1981. v. 6, 55p. 